\title{
Effectiveness of a UVC air disinfection system for the HVAC of an ICU
}

\author{
Susana Oliveira de Souza ${ }^{1, \mathrm{a}}(\mathbb{D})$, Antônio Américo Cardoso $\mathbf{J r}^{2}$, \\ Aquiles Sales Craveiro Sarmento ${ }^{3}$ (D) , Francesco d'Errico ${ }^{1,4,5}$ (D)
}

${ }^{1}$ Departamento de Física, Universidade Federal de Sergipe, São Cristóvão, SE 49100-000, Brazil

2 Departamento de Ciências Florestais, Universidade Federal de Sergipe, São Cristóvão, SE 49100-000, Brazil

${ }^{3}$ Empresa Brasileira de Serviços Hospitalares, Hospital Universitário de Lagarto, Lagarto, SE 49400-000, Brazil

${ }^{4}$ Scuola di Ingegneria, Università di Pisa (UNIPI), Pisa, Italy

${ }^{5}$ Yale University and Yale Center for Emergency Preparedness and Disaster Response, New Haven, CT, USA

Received: 10 January 2021 / Accepted: 27 November 2021

(C) The Author(s), under exclusive licence to Società Italiana di Fisica and Springer-Verlag GmbH Germany, part of Springer Nature 2021

\begin{abstract}
Ultraviolet germicidal irradiation (UVGI) uses short-wave ultraviolet (UVC) light to inactivate organisms like viruses, bacteria, and fungi. UVC inactivates a wide range of microorganisms by damaging the structure of nucleic acids and proteins at the molecular level, so they become unable to replicate and cause disease. Thus, UVC can improve indoor air quality by controlling bioaerosols and can be used as an engineering device to interrupt the transmission of pathogenic organisms and potential bioterrorism agents. Recently, the World Health Organization recognized that the COVID-19 virus could be transmitted across large distances, suggesting that indoor ventilation is key in airborne transmission. As a test for the future dissemination of UVC light installations to improve indoor air quality in Hospitals in Sergipe State, Brazil, we made a first installation of UVGI disinfection lamps, strategically placed in the Heating, Ventilating, and Air Conditioning (HVAC) system of the Intensive Care Unit (ICU) at the University Hospital of Lagarto, Federal University of Sergipe, Brazil. Six $15 \mathrm{~W}$ low-vapor-pressure mercury lamps emitting $253.7 \mathrm{~nm}$ UVGI were installed in the ducts of the fan coil, maximizing their luminous interaction in the air passage. One of the greatest advantages of this type of installation is that the lamps were completely covered, avoiding any risk of hazardous exposure to people and animals. Microbiological tests were carried out to verify the germicidal effect, analyzing the viability of microorganisms circulating in the environment. In this paper, we present our encouraging results, demonstrating the effectiveness of the installation, suggesting that similar devices should be installed in HVAC systems to avoid biological risk to people inside buildings. In addition, we believe that this study may provide useful evidence and guidance for the design of equipment intended to abate the microorganisms that may be used in CBRNE terror attacks.
\end{abstract}

\footnotetext{
a e-mail: sosouza@academico.ufs.br (corresponding author)
} 


\section{Introduction}

Multiresistant strains of airborne infectious agents have proliferated worldwide in recent years. Furthermore, disinfection and decontamination to mitigate biological threats to people congregating within buildings have assumed great importance due to the recognized increase in threats of bioterrorism [1], in addition to the pandemic of COVID-19.

Ultraviolet germicidal irradiation (UVGI) radiation has been studied by several researchers and used extensively for over 40 years in the disinfection of water, air, laboratories, pharmaceutical products, and surfaces in general against human pathogens. While ultraviolet (UV) is the denomination of any radiant energy with a wavelength between 100 and $400 \mathrm{~nm}$, UVGI uses mainly short-wave ultraviolet (UVC) light. The UVC range is $100-280 \mathrm{~nm}$, the most effective wavelength range of UVGI for the inactivation of microorganisms is 250 to $270 \mathrm{~nm}$, and the maximum effectiveness is at $265 \mathrm{~nm}$. The UV radiation emitted by the Sun and reaching the surface of the Earth falls in the spectral UV regions called UVA and UVB, which are less energetic, while the UVC from the Sun is blocked by the ozone layer. Used for decades in healthcare facilities, UVGI is known to inactivate microorganisms on surfaces and airborne, limiting their ability to grow and multiply when inhaled or aspirated. UVC radiation is strongly absorbed by proteins and nucleic acids, such as DNA and RNA, which makes it an efficient method of abating pathogens, since it generates significant changes in their nucleic acids, leaving them unable to perform important metabolic functions [2, 3].

Each different organism has a different sensitivity to UVGI. Malayeri et al. [4] compiled data from several studies on the UV dose necessary to achieve inactivation of bacteria, protozoa, viruses, and algae, i.e., the loss of their reproductive capacity. There are differences in susceptibility to UVC disinfection, but all tested organisms, including various coronaviruses, responded well when exposed to appropriate doses. Doses between 0.5 and $1.8 \mathrm{~J} / \mathrm{cm}^{2}$ have shown $99.9 \%$ antimicrobial efficacy for all tested viruses [5]. Tseng and Li assessed that UVGI doses of 2 to $5 \mathrm{~mJ} / \mathrm{cm}^{2}$ were sufficient to inactivate single-stranded RNA viruses of the same type as SARS-CoV-2 [6]

Due to the COVID-19 pandemic, UVGI disinfection was taken into consideration by the American government given the scarcity of N95 respirators on the market, having been authorized by the Food and Drug Administration (FDA) in March 2020, for the USA [7]. According to the US Centers for Disease Control and Prevention (CDC), UVGI is a favorable method for disinfecting FFRs, but its effectiveness depends on the dose applied [5]. Therefore, UVGI disinfection has been recognized as an important tool in mitigating damage by pathogens, including SARS-CoV-2. Several studies have recently emerged showing that UVC radiation can cause SARS-CoV-2 to be inactivated, as well as many other pathogens $[8,9]$ Bianco et al. [10] used a low-pressure $\mathrm{Hg}$ lamp system, emitting $253.7 \mathrm{~nm}$ with $1.082 \mathrm{~mW} / \mathrm{cm}^{2}$, and obtained total virus inactivation of low viral loads with a dose smaller than $4 \mathrm{~mJ} / \mathrm{cm}^{2}$, while higher viral loads were inactivated with a dose of $16.9 \mathrm{~mJ} / \mathrm{cm}^{2}$. Inagaki et al. [11] applied another type of UV source against SARS-CoV-2. They used an LED emitting $280 \mathrm{~nm}$ "deep ultraviolet" radiation (DUV-LED) with a dose rate of $3.75 \mathrm{~mW} / \mathrm{cm}^{2}$. They were able to inactivate $87.4 \%$ of the virus within $1 \mathrm{~s}$ and over $99.99 \%$ within $20 \mathrm{~s}$ at a distance of $20 \mathrm{~mm}$ from the source.

Water disinfection is currently the most advanced and widely accepted germicidal application of UVC. However, air disinfection is also performed using UVC in various modalities: air irradiation from the ceiling exposing only the upper part of a room, irradiation of an entire room (when the room is not occupied or protective clothing and goggles are used), and irradiation of the air circulating through an HVAC (Heating, Ventilation and Air Conditioning) system [12]. Major efforts are ongoing worldwide to develop appropriate methods of UVGI 
disinfection of the air, water, and surfaces; however, a deeper understanding of the potential for UV disinfection in each type of system is still needed.

Systems to inactivate viruses, such as the coronavirus that causes the current global pandemic, can be extremely useful in environments highly prone to the spread of microorganisms. Thus, UVGI can improve indoor air quality by controlling bioaerosols and can be used as an engineering device to interrupt the transmission of pathogenic organisms and potential bioterrorism agents. This work deals with the application of equipment built to inactivate microorganisms in the air flow of the HVAC system of an Intensive Care Unit (ICU) of the University Hospital of the Federal University of Sergipe in the City of Lagarto, SE, during the pandemic of COVID-19.

\section{Materials and methods}

For the development of an UVGI disinfection system for HVACs, a multidisciplinary team of experts in the detection and use of ultraviolet light, as well as technicians and engineers, was formed. Our R\&D work started with the adoption of the qualitative research method. Qualitative research methods in the health sciences study the nature of a phenomenon and are especially appropriate for addressing why something is observed (or not), assessing complex multi-component interventions, and focusing on intervention improvement.

The first task was the definition of the most suitable equipment components and the location for the installation of the disinfection system. The Lagarto University Hospital (HUL), associated with the Federal University of Sergipe (UFS), was chosen due to the strong collaboration record of the research team, which intensified during the COVID-19 pandemic. In agreement with the hospital team, we chose an HVAC system whose structure has closed ducts, and which directs the airflow to an ICU. It was decided to install a UVGI device in an HVAC duct to avoid exposure of humans and animals to UVC light. Then, a team of technicians was sent to the site and the HVAC system was examined to check its airflow and dimensions in order to appropriately design and easily install our UVGI equipment.

For the construction of the equipment, six $15 \mathrm{~W}$ Osram UVGI fluorescent tubes containing low-pressure $\mathrm{Hg}$ vapor were placed on a regular array every $14.5 \mathrm{~cm}$ and secured with an aluminum frame. On a side of this structure, the six reactors necessary for the operation of the lamps were placed, in a position causing minimal shadowing on the airflow.

Photographs of the equipment (Fig. 1) show the aluminum frame built as planned to accommodate all lamps. The dimensions of the frame are $48.0 \mathrm{~cm} \times 29.5 \mathrm{~cm}$. The width allows an optimal spacing of the lamps within the HVAC of the HUL, covering the entire air outlet, while the height allows installation of the lamps vertically in the sockets affixed to the frame. The reactors, necessary for this type of lamp, were placed laterally in an acrylic box protecting them from UVC exposure and attached to the aluminum frame as shown in Fig. 1. The required long electrical cable was also affixed externally with a socket connecting the lamps to the electrical power. The UVGI system was made for operation at $220 \mathrm{~V}$, which is the same voltage as the HVAC equipment. The germicidal lamps were connected in parallel to the power supply.

The UV dose $\left(\mathrm{J} / \mathrm{m}^{2}\right)$ is given by the fluence rate integrated over the exposure time [13]. The most common units are $\mathrm{W} / \mathrm{cm}^{2}$ for the fluence rate and $\mathrm{mJ} / \mathrm{m}^{2}$ for $\mathrm{UV}$ dose. The fluence rate varies strongly based on the power rating of a lamp and on the distance from the lamp. The design target dose of UV must produce a significant reduction in the viability of the microorganisms. 

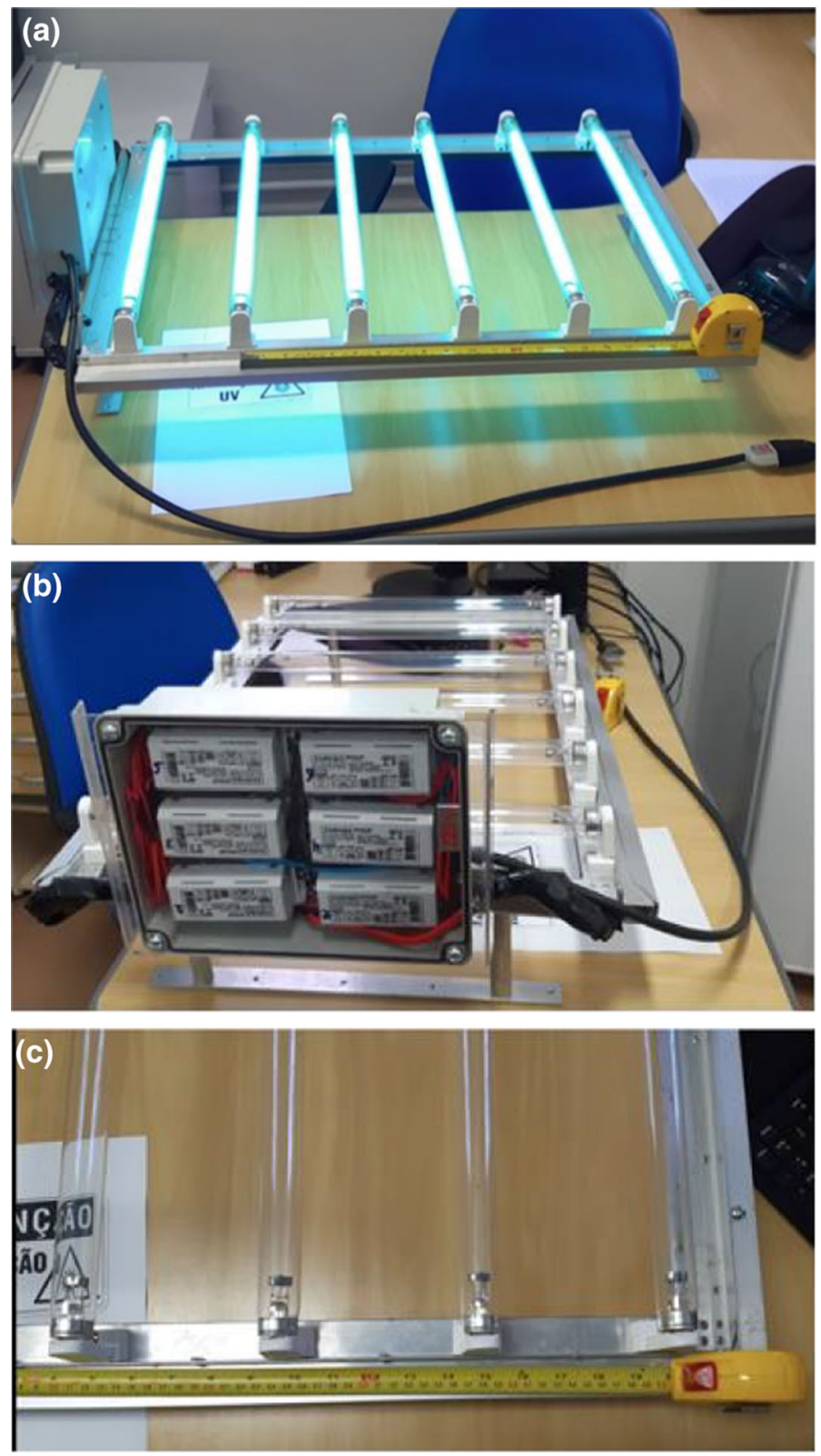

Fig. 1 Photograph of the UVC disinfection equipment for the HVAC system at HUL. a View of the equipment with the lights on. b Reactors inside an acrylic electrical box. c Spacing between the lamps in the structure

To determine the lamp emission rate, measurements of the UVC dose rate from the same kind of lamps were performed using a mask disinfection cabinet previously designed and installed at the hospital [14]. For this task, we used a UVC GenUV radiometer (Daejeon, South Korea). The radiometer was positioned at different heights from the base of the cabinet and at different orientations with respect to the lamps as shown in Fig. 2. The emission spectrum of 


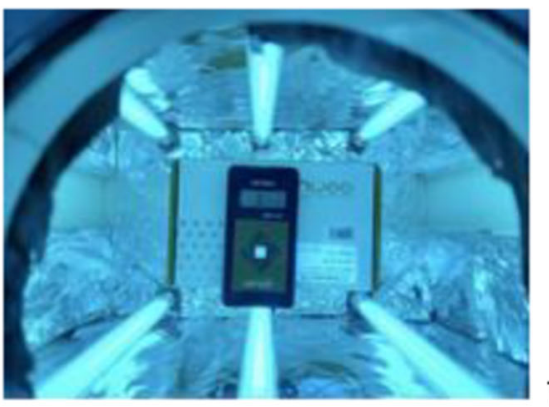

1)

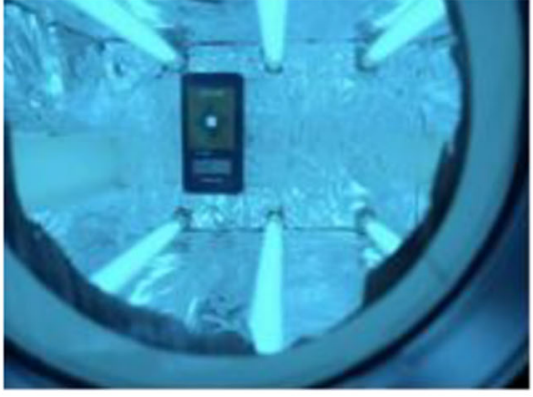

2)
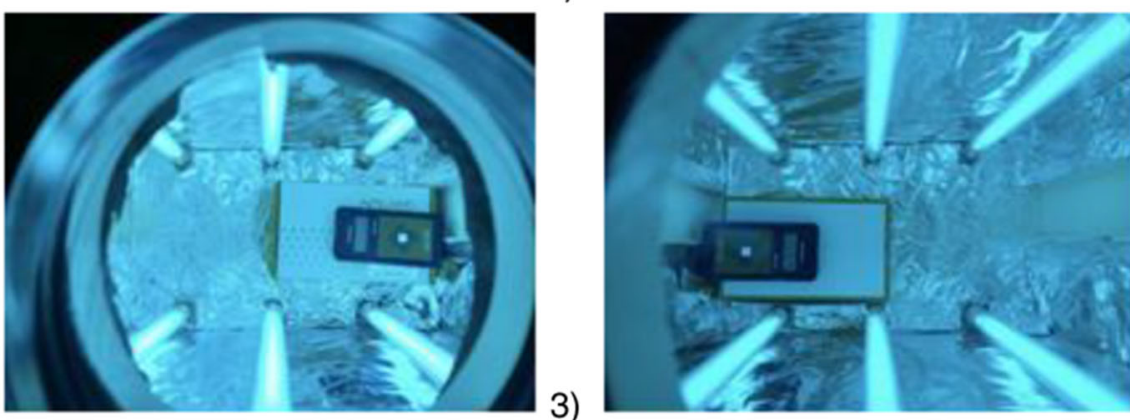

4)

Fig. 2 Positioning of the radiometer in different UVC cabinet positions concerning the lamps. 1. Radiometer placed in front of one of the lamps; 2. radiometer placed between two lamps; 3 . radiometer placed across the lamp arrays (right direction); 4. radiometer placed across the lamp arrays (left direction)

Table 1 Experimental design to evaluate the effectiveness of the presence of UVC light in the HVAC against microorganisms. The incubation time was 8 days for all plates

\begin{tabular}{lll}
\hline Petri dish \# & Air condition & Incubation temperature $\left( \pm 2{ }^{\circ} \mathrm{C}\right)$ \\
\hline 1 & Exposure to the air flux after shutdown of UVC & 35 \\
2 & & 21 \\
3 & & \\
4 & & 35 \\
5 & Exposure to the air flux after 24 h of UVC being on & \\
6 & & 21 \\
7 & & \\
8 & & \\
\hline
\end{tabular}

the lamps was also measured using a compact CCD spectrometer (Ocean Optics QE65000) connected to an optical fiber collecting the light emitted into the cabinet.

A bacteriological study on Gram-negative bacilli was carried out at the HUL to test the efficiency of ultraviolet light. For this test, $1 \mu \mathrm{L}$ of Gram-negative bacteria with a turbidity of 0.5 on the McFarland scale (McF) was spread for cell seeding in three plates of horse blood agar. A control plate was not exposed to ultraviolet light, and two were separately exposed, respectively, to UVC light inside the UVC cabinet developed by the team, and in a Class II Biological Safety Cabinet (CSB) used as a reference. The test was repeated for UVC light exposures of 2, 5, and $10 \mathrm{~min}$. 
To assess the effectiveness of the lamps in the HVAC system, the HUL microbiology group conducted a first microbiology test. First, four horse blood agar plates were directly exposed for $15 \mathrm{~min}$ to the air gushing from an HVAC vent in the HUL ICU (Fig. 1b). On that occasion, the UVC equipment had been previously kept off for $24 \mathrm{~h}$ to allow microbial proliferation within the air conditioning ducts. In a second measurement, the UVC system was kept on for $24 \mathrm{~h}$ and another four blood agar plates were subjected to the same treatment. The eight plates were then incubated separately, according to the experimental design scheme shown in Table 1.

\section{Results and discussion}

Our objective was to design UVGI air disinfection equipment that could be rapidly produced and deployed in the HVAC systems of hospitals and emergency care units. Thus, we needed to optimize the project, adopting effective and low-cost solutions that could assist health professionals practically and safely. A photograph of the installation on-site is shown in Fig. 3. The door of the HVAC equipment was opened for photography only. It is permanently closed, and a caution notice for UVC light is installed on the front door to avoid exposure risks by opening it. We also recommend the installation of an external warning lamp to signal problems with power outages that can cause the equipment to be inadvertently switched off.

The emission spectrum of the UVC light bulb (Fig. 4) shows several lines emitted as expected by the low-pressure $\mathrm{Hg}$ vapor lamps; among them, a line at $253.7 \mathrm{~nm}$ stands out, providing the desired UVGI.

In general, the UVC power is only about 20 to $30 \%$ of the nominal power rating of a mercury lamp. Each lamp used in this project has a nominal power of $15 \mathrm{~W}$. Therefore, about 3 to $4.5 \mathrm{~W}$ was estimated to be their effective UVC power rating. This power is distributed unevenly across the tube, being lower at its ends, and decreasing rapidly with the distance from the lamp. To ensure that the dose required for air decontamination is delivered, it is necessary to determine the flux of radiant energy. Thus, using a NIST traceable calibrated UVC radiometer we measured the dose rate at different points inside a mask decontamination cabinet. Measurements were performed inside a medium-density fiberboard (MDF) box with three lamps on the one side and three lamps on the opposite side; the measurements were taken before and after lining most of the internal surfaces with aluminum. The results are shown in Table 2.

As can be derived from Table 2, the average dose rate in the UVC cabinet was $(2.7 \pm 0.5) \mathrm{mW} / \mathrm{cm}^{2}$ before lining with aluminum foil. After lining was applied to about $94 \%$ of the internal surfaces, the average dose rate became much more uniform and increased by about a factor of 3 , reaching $(8.6 \pm 0.3) \mathrm{mW} / \mathrm{cm}^{2}$.

The observed gain is consistent with our first-order estimates based on treating the cabinet as two reflecting planes with minimal lateral loss. We estimated the total reflectance $\mathrm{R}$ inside the cabinet as the product of the geometric efficiency (94\%, corresponding to the percentage of surface lining) and the inherent reflectivity of the lining ( $70 \%$ for unblemished, shiny aluminum foil). We then estimated the gain as $G=1 /(1-\mathrm{R}) \sim 2.9$, which is consistent with the measured value.

The ducts of the HVAC equipment do provide some UVC reflectance, especially when the equipment is new, or the ducts have been recently cleaned. However, the gain estimates indicate that, in order to achieve a significant reflectance, an HVAC duct should be lined thoroughly, and the reflectance of the lining should be high and constant over time. These two conditions are difficult to meet, given the geometry of the ducts and the inevitable 

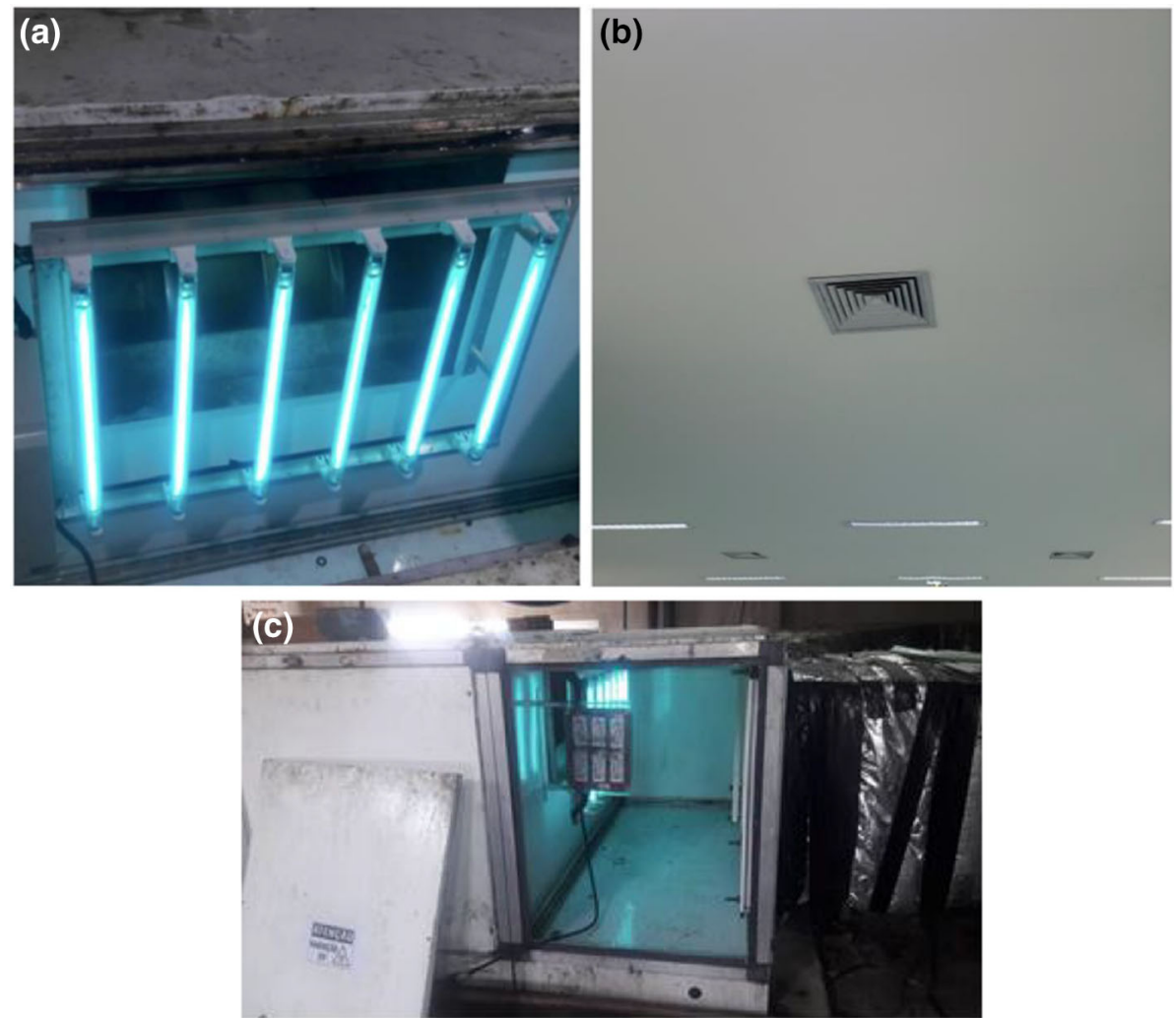

Fig. 3 a Six ultraviolet lights installed in the air conditioning duct. b Exit of the HVAC flow inside the ICU where the microorganisms were collected in the petri dishes. c Overview of the HVAC duct with the UVC system installed and connected - the equipment door was opened only for photography — a caution notice for UVC light was installed in it

Fig. 4 Emission spectrum of lamps in the UVC cabinet

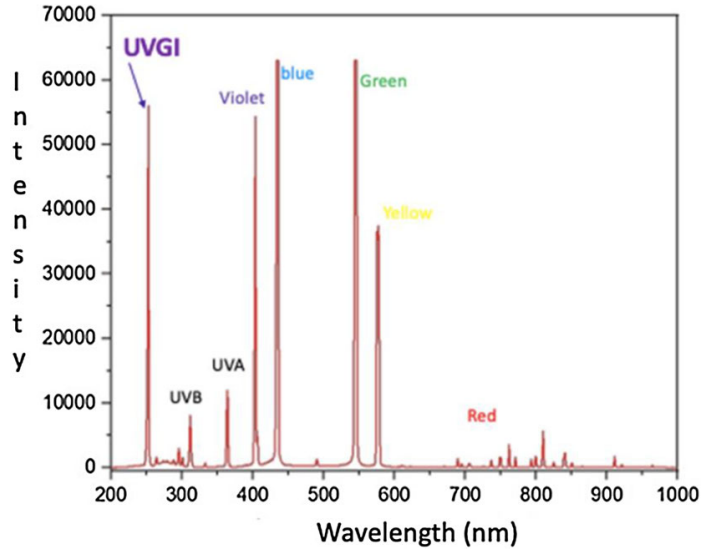


Table 2 Dose rates recorded in the central region of the UVC cabinet measured in different positions at different heights from the bottom of the cabinet

\begin{tabular}{lcc}
\hline Position inside the cabinet & $\begin{array}{l}\text { Without aluminum foil } \\
\text { Dose rate }\left(\mathrm{mW} / \mathrm{cm}^{2}\right)\end{array}$ & $\begin{array}{l}\text { With aluminum foil } \\
\text { Dose rate }\left(\mathrm{mW} / \mathrm{cm}^{2}\right)\end{array}$ \\
\hline $0.0 \mathrm{~cm}$ from the base & $0.57 \pm 0.19$ & $8.5 \pm 0.5$ \\
$6.5 \mathrm{~cm}$ from the base & $3.6 \pm 0.7$ & $8.6 \pm 0.5$ \\
$12.0 \mathrm{~cm}$ from the base & $2.3 \pm 0.5$ & $8.4 \pm 0.5$ \\
$18.5 \mathrm{~cm}$ from the base & $3.0 \pm 0.6$ & $8.2 \pm 1.0$ \\
$27.0 \mathrm{~cm}$ from the base & $4.0 \pm 0.6$ & $10.2 \pm 0.5$ \\
$36.0 \mathrm{~cm}$ from the base & $3.0 \pm 0.5$ & $7.5 \pm 0.2$ \\
Cabinet average & $2.7 \pm 0.5$ & $8.6 \pm 0.3$ \\
\hline
\end{tabular}

(a)

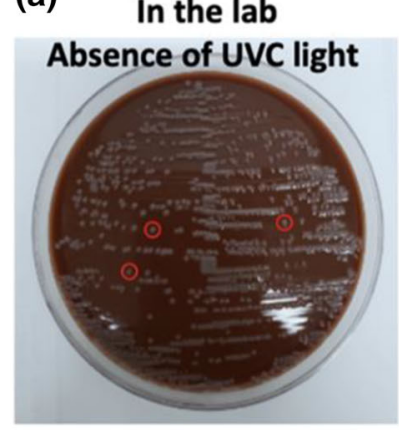

Presence of bacterial growth (b) Chemical hood 2 min of UVC exposure

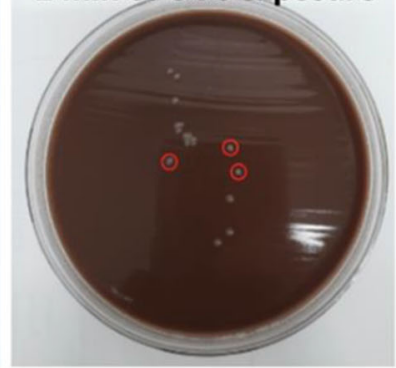

Presence of bacterial growth (c) Our cabinet-
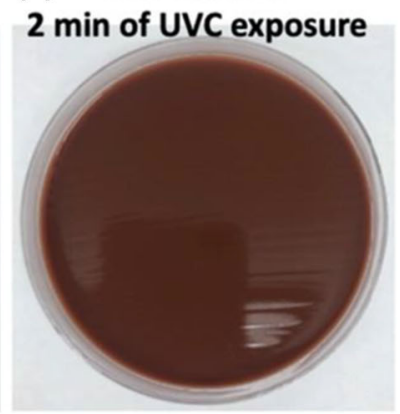

Absence of bacterial growth

Fig. 5 Results of the first bacteriological study on Gram-negative bacilli. a In the absence of UV light: the presence of bacterial growth (highlighted in red circles). b In the presence of UV light for 2 min from Class II Biological Safety Cabin: the presence of some bacterial growth (highlighted in red circles). $\mathbf{c}$ In the presence of UV light from the cabinet: no significant bacterial growth

deterioration of the reflectivity when the internal surfaces are exposed to a flux of air carrying humidity and particles, as well as to a constant flux of UVC. This aspect of the operation of our HVAC disinfection system is currently being investigated.

The first bacteriological study on Gram-negative bacilli demonstrated that the UVC cabinet has good antibacterial effectiveness. Three tests of exposure to UVC light, of 2, 5, and $10 \mathrm{~min}$, were performed in our UVC mask disinfection cabinet and another in a Class II CSB cabin, for comparison purposes. In each test, a third control plate was seeded but not exposed to UVC light. After $24 \mathrm{~h}$ of incubation at $(35 \pm 2){ }^{\circ} \mathrm{C}$, the un-exposed control plate presented elevated growth in the three tests performed (Fig. 5a). A plate exposed for two minutes in the Class II CSB and incubated for $24 \mathrm{~h}$ also showed some growth of bacilli (Fig. 5b), but exposures of 5 and 10 min prevented significant microbial development. It should be noted that the recommended disinfection time is $15 \mathrm{~min}$ for this Cass II CSB. On the other hand, the plate seeded and exposed for 2, 5, and 10 min inside our UVC mask disinfection cabinet presented no significant microbial growth (Fig. 5c), indicating elevated antibacterial 

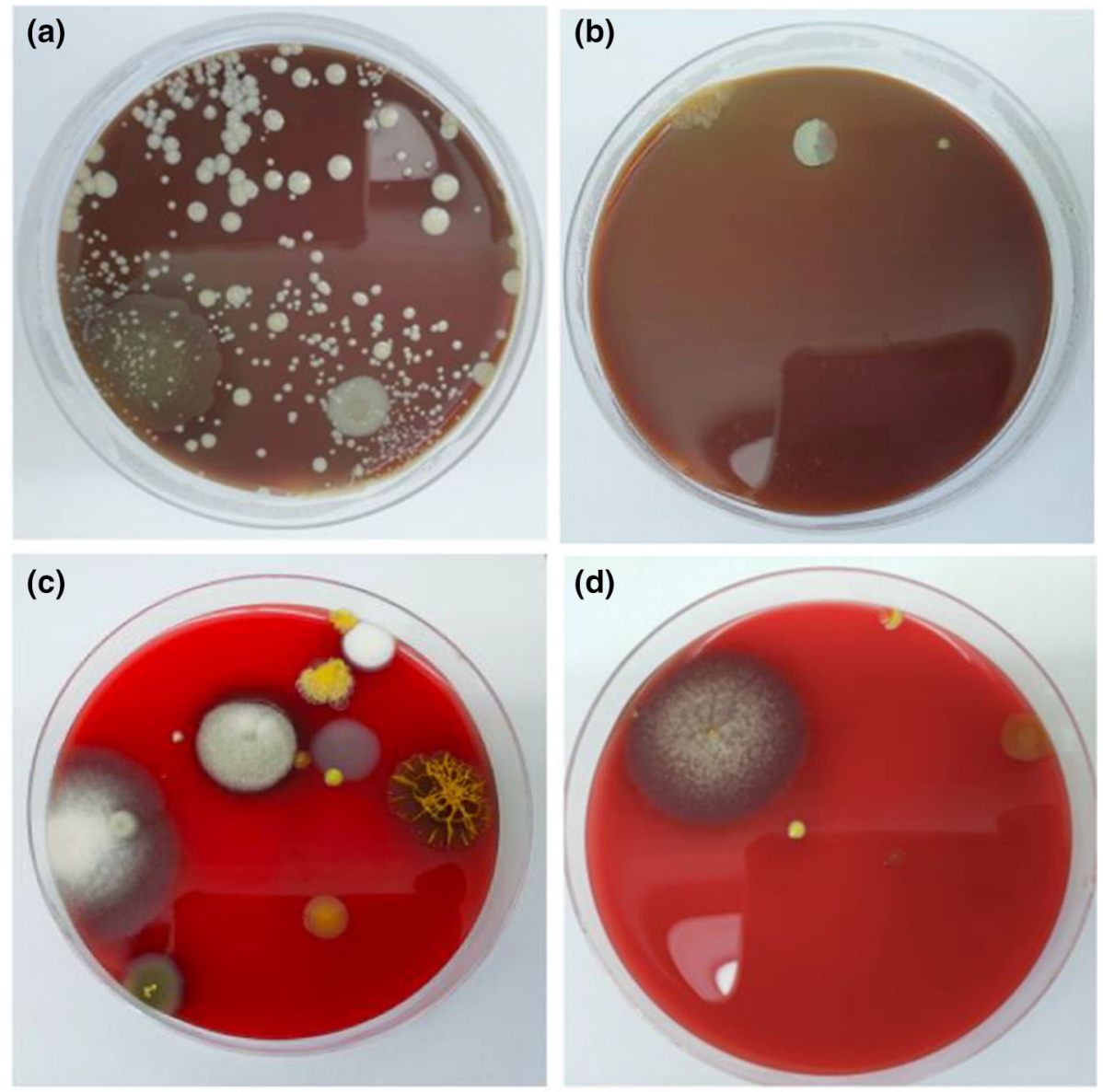

Fig. 6 Petri dishes exposed to air after keeping the UVC equipment off for $24 \mathrm{~h}$. a-b Incubation temperature $(35 \pm 2){ }^{\circ} \mathrm{C}$; c-d incubation temperature $(21 \pm 2){ }^{\circ} \mathrm{C}$

effectiveness. The repetition of these tests in triplicate, as well as the execution of tests over even shorter times, is currently in progress.

The plates exposed to the HVAC air flow after keeping the UV light off for $24 \mathrm{~h}$ showed significant growth of microorganisms, at both $(35 \pm 2){ }^{\circ} \mathrm{C}\left(\right.$ Fig. 6a-b) and $(21 \pm 2){ }^{\circ} \mathrm{C}$ (Fig. 2c-d). Indeed, it was possible to count over 150 colonies in the four plates. Conversely, after the UV light had been kept on for $24 \mathrm{~h}$, there is no significant growth of microorganisms after exposure of the plates to the air from the same HVAC vent, at both $(35 \pm 2){ }^{\circ} \mathrm{C}$ (Fig. $\left.7 \mathrm{a}-\mathrm{b}\right)$ and $(21 \pm 2){ }^{\circ} \mathrm{C}$ (Fig. $\left.7 \mathrm{c}-\mathrm{d}\right)$. In this case, it was possible to count only 16 colonies on the four plates.

Due to safety restrictions, it was not possible to perform tests on actual viruses and it is not possible to directly apply our results to claim microbicidal effectiveness against viruses. Nevertheless, the bactericidal effect of the lamps installed in the ICU air conditioning duct was clearly validated in our screening approach. Clear differences were observed between the number of colonies in the plates exposed to untreated air, compared to the group that was exposed to air disinfected by UVC light. These first experiments did not include an accurate 

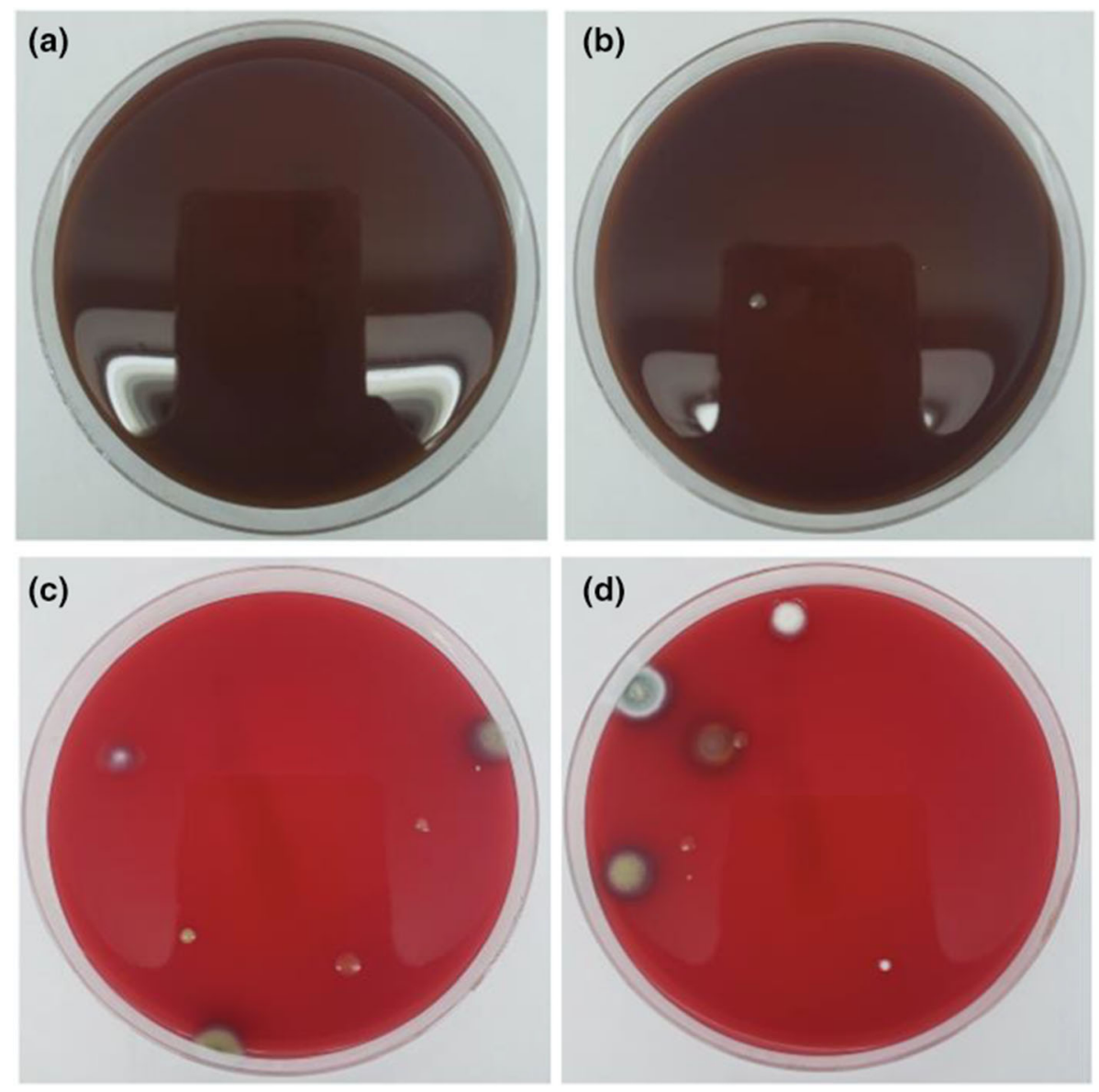

Fig. 7 Petri dishes exposed to air after keeping the UVC equipment on for $24 \mathrm{~h}$. $\mathbf{a}-\mathbf{b}$ Incubation temperature $(35 \pm 2){ }^{\circ} \mathrm{C}$; c-d incubation temperature $(21 \pm 2){ }^{\circ} \mathrm{C}$

control of the air flow impinging on the plates, which were held manually in front of the HVAC vent. In addition, only one HVAC vent was tested. Therefore, more numerous and rigorous tests, in more locations and with more culture media, are necessary to provide proof of effective decontamination. The authors are currently consulting a company specializing in air quality control in order to overcome the limitations of this first study. In addition, even though manufacturers frequently claim that their lamps are ozone-free, we plan to perform tests on the possible presence of ozone gas, which can be generated by ultraviolet radiation below $240 \mathrm{~nm}$, to establish whether its concentration is indeed below the allowed limit.

\section{Conclusions}

We designed, built, and tested a UVGI disinfection setup for HVAC systems, which is now being offered for independent evaluation by interested users, within a scientific research cooperation, to mitigate the effects of the pandemic on health professionals and patients 
within hospitals. Our equipment is meant to reduce the viral load in the airflow, thus reducing the risk of spreading contamination.

Similar devices could be installed in HVAC systems to minimize biological risk to people inside buildings. In addition, we believe that this study may provide useful evidence and guidance for the design of equipment intended to abate the microorganisms that may be used in CBRNE terror attacks.

Acknowledgements The authors would like to thank the collaborators in the carpentry and electrical maintenance sector of the Prefecture of the Federal University of Sergipe who collaborated in the execution of the equipment. The authors would also like to thank the board of the Hospital Universitário de Lagarto for their collaboration in the work.

Author's contributions SOS performed conceptualization, funding acquisition, project management, and writing-original draft; SOS and ASCS helped in formal analysis; SOS, AACJ, and ASCS investigated the data; AACJ and ASCS were involved in experimental activities; SOS, AACJ, and ASCS contributed to methodology; SOS and F.dE contributed to supervision and writing-review and editing. All authors have read and agreed to the published version of the manuscript.

Funding This work was funded in part by the Federal University of Sergipe (UFS), by the Brazilian National Council for Scientific and Technological Development (CNPq), and by the Coordination for the Improvement of Higher Education Personnel (CAPES).

\section{Declarations}

Conflict of interest The authors declared that there is no conflict of interest.

\section{References}

1. CIE - Commission Internationale de l'Eclairage, Technical report: ultraviolet air disinfection, Vienna: CIE 155/2003, 2003

2. W. Kowalski, Ultraviolet Germicidal Irradiation Handbook: UVGI for Air and Surface Disinfection, 1a. Ed. Springer, 2009

3. D. Weber, W. Rutala, E. Sickbert-Bennet, H. Kanamori, D. Anderson, Continuous room decontamination technologies. Am. J. Infect. Control 47, 72-78 (2019)

4. A.H. Malayeri, M. Mohseni, B. Cairns, J.R. Bolton, G. Chevrefils, E. Caron, B. Barbeau, H. Wright and K.G. Linden, "Fluence (UV Dose) Required to Achieve Incremental Log Inactivation of Bacteria, Protozoa, Viruses and Algae,” 2020. [Online]. Available: https://www.iuvanews.com/stories/pdf/archives/ 180301_UVSensitivityReview_full.pdf. [Accessed 18 June 2020]

5. CDC - Center for Disease Control and Prevention, Decontamination and Reuse of Filtering Facepiece Respirators, 2020. [Online]. Available: https://www.cdc.gov/coronavirus/2019-ncov/hcp/ppe-strategy/ decontamination-reuse-respirators.html. [Accessed 1 June 2020]

6. C.C. Tseng, C.S. Li, Inactivation of viruses on surfaces by ultraviolet germicidal irradiation. J. Occup. Environl Hyg. 4(6), 400-405 (2019)

7. FDA - U.S. Food and Drugs Administration, "Emergency use authorization: Batelle Decontamination System,” 2020. [Online]. Available: https://www.fda.gov/media/136529/download. [Accessed 1 June 2020]

8. M. Darnell, K. Subbarao, S.M. Feinstone, D. Taylora, Inactivation of the coronavirus that induces severe acute respiratory syndrome. SARS-CoV. J Virol Methods 121(1), 85-91 (2004)

9. H. Kariwa, N. Fujii, I. Takashima, Inactivation of SARS Coronavirus by Means of Povidone-Iodine. Phys. Cond. Chem. Reage. Dermatol. 212, 119-123 (2006)

10. A. Bianco, M. Biasin, G. Pareschi, A. Cavalieri, C. Cavatorta, C. Fenizia, P. Galli, L. Lessio, M. Lualdi, E. Redaelli, I. Saulle, D. Trabattoni, A. Zanutta, M. Clerici, UV-C irradiation is highly effective in inactivating and inhibiting SARS-CoV-2 replication, medRxiv preprint, 2020

11. H. Inagaki, A. Saito, H. Sugiyama, T. Okabayashi and S. Fujimoto, Rapid inactivation of SARS-CoV-2 with Deep-UV LED irradiation, bioRxiv preprint, 2020 
12. G.F. Reed, H.A. Al Hassan, M.J. Korytowski, P.T. Lewis, B.M. Grainger, Comparison of HVAC and HVDC solutions for offshore wind farms with a procedure for system economic evaluation, IEEE Energytech (2013). https://doi.org/10.1109/EnergyTech.2013.6645302

13. J.R. Bolton, S. Beck and K.G. Linden, Protocol for the determination of fluence (UV dose) using a lowpressure or low-pressure high-output UV lamp in benchscale collimated beam ultraviolet experiments, 2021. [Online]. Available: https://www.iuva.org/resources/Resource\%20Documents/Bolton-Protocol\% 20for\%20the\%20Determination\%20of\%20Fluence.pdf. [Accessed 8 January 2021]

14. S. de Souza, C.L.S. dos Prazeres, J.S. Vieria, W. Almeida, A.S.A.C. Sarmento, P.V.D. da Cruz, J.J. Rodrigues Junior, E.N. Oliveira, M.R.P. Attie, and W.M. da Silva Júnior, UVC cabin development for N95 medical masks disinfection, Revista Interdisciplinar de Pesquisa e Inovação COVID 197(2), 17-30 (2020) 